\title{
EVIDENCIA DE LA PRESENCIA DE ANTICUERPOS DE Mycoplasma hyopneumoniae EN CERDOS PROVENIENTES DE GRANJAS DE CRIANZA ARTESANAL DEL SUR DE LIMA
}

\author{
Marco Ibarra C. ${ }^{1}$, Norma Noé M. ${ }^{2}$, Arnaldo Alvarado S. ${ }^{2}$ y Rosa Perales C. ${ }^{2}$
}

\section{Abstract}

A total of 160 eight to nine month old pigs from poorly managed farms in four districts of southern Lima were tested by ELISA to determine the presence of Mycoplasma hyopneumoniae antibodies. The samples were collected at two slaughterhouses in the Lima valley. The incidence of positive animals was $11.25 \%(18 / 160)$, with no significant correlation between the presence of positive animals and geographic area if origin found using the Chi-Square test.

Key words: Enzootic pneumonia, Mycoplasma hyopneumoniae, ELISA.

\section{Resumen}

Se realizó un estudio para determinar la presencia de anticuerpos de Mycoplasma hyopneumoniae en cerdos provenientes de granjas de crianza artesanal, mediante la detección de anticuerpos, utilizando el ensayo inmuno absorbente ligado a enzimas (ELISA). Ciento sesenta animales de 8 a 9 meses de edad procedentes de granjas de 4 distritos ubicados al Sur de Lima, fueron muestreados al momento de ser beneficiados en 2 camales frigoríficos del valle de Lima. Se obtuvo una frecuencia de animales positivos del 11.25\% (18/160), demostrándose la presencia de anticuerpos del microorganismo bajo esta modalidad de crianza. Mediante el uso de la prueba de Chi Cuadrado no se encontró asociación estadística significativa entre la presencia de seroreactores positivos y el área geográfica de donde provenían los animales.

Palabras Claves: Neumonía enzoótica, Mycoplasma hyopneumoniae, ELISA

\section{Introducetón}

La infección por las diferentes especies de Mycoplasma tiene un papel importante como limitante de una adecuada producción de cerdos, no sólo en nuestro país, sino en diversas partes del mundo. Dentro de ellas, la especie $M$. hyopneumoniae es la causante de una de las enfermedades respiratorias de mayor impacto en la producción porcina, originada por una disminución de la

\footnotetext{
'Práctica privada

${ }^{2}$ FMV - UNMSM. Lima Perú. Apdo. 41-0068
}

velocidad de crecimiento y una reducción en la eficiencia alimenticia (Hill et al., 1992 y Copes et al., 1995). El microorganismo habita en el tracto respiratorio de los cerdos, y es eliminado en las secreciones respiratorias, infectándose cerdos susceptibles. Los lechones se infectan por las secreciones respiratorias de las madres después de las 4 a 6 semanas de vida, ya que durante las primeras semanas están protegidos por los anticuerpos maternos recibidos (Kobisch y Friis, 1996).

La mayor incidencia clínica y patológica de neumonía enzoótica ocurre luego del destete y en la mayoría de los casos, 
continúa durante el período de crecimiento o hasta la edad comercial de los animales (Gardner y Hird, 1990).

En los rebaños infectados, la tasa de mortalidad es de 1 a $5 \%$, es menor que la de morbilidad, la que alcanza su nivel más alto (40 a 60\%) a los 4 a 6 meses de edad declinando luego (Stipkovits, 1995).

La importancia de $M$. hyopneumoniae se debe, además de su efecto como patógeno primario, a su capacidad para actuar sinérgicamente con otros agentes infecciosos y producir una neumonía grave. Puesto que las infecciones secundarias son comunes, se piensa que la infección por este microorganismo puede predisponer al huésped a una invasión subsecuente por diversos patógenos, tales como Actinobacillus pleuropneumoniae (Carusso y Ross, 1990) y Pasteurella multocida (Amass et al., 1994).

Se ha señalado también que $M$. hyopneumoniae está involucrado, con el virus del Síndrome Reproductivo y Respiratorio Porcino (PRSS), Pasteurella multocida, Streptococcus suis y Actinobacillus pleuropneumoniae, en el Complejo Respiratorio Porcino (Boeckman 1996; Dee 1997).

En el Perú, Vega (1969), realizó un estudio en un matadero de Lima, en base al hallazgo de lesiones macroscópicas y microscópicas, y determinó la presencia de neumonía enzoótica en 40 de 100 pulmones de cerdos examinados. Torres (1992), al evaluar las lesiones pulmonares que determinan el decomiso del pulmón de cerdo, encontró que de 100 pulmones de animales examinados al matadero existían lesiones que se podían atribuir a neumonía enzoótica en una frecuencia de $11 \%$. Huallanca (1999), utilizó la prueba de ELISA para determinar cerdos seroreactores a $M$. hyopneumoniae procedentes de granjas tecnificadas del valle de Lima, encontrando una frecuencia de $12.2 \%$. Anteriormente en el Perú no se había logrado demostrar la presencia de este microorganismo, a pesar de la importancia de esta enfermedad.

Siendo la neumonía enzoótica una enfermedad limitante de la producción, y la crianza artesanal de cerdos un sistema productivo muy importante, el objetivo del presente trabajo fue establecer la presencia del $M$. hyopneumoniae en granjas de cerdo tipo artesanal mediante el examen serológico en animales en edad de beneficio utilizando la prueba de ELISA indirecta.

Para el cálculo del tamaño muestral se utilizó la fórmula de prevalencia límite (Ahlbom y Novell, 1990) utilizando un nivel de confianza de $99 \%$.

Se tomó como prevalencia límite el valor de $3.3 \%$, que fue el menor valor encontrado en 7 granjas tecnificadas realizado por Huallanca (1999). El tamaño mínimo de la muestra fue de 152 y se trabajó con 160 animales.

Las muestras de sangre fueron obtenidas al momento del beneficio de los cerdos en dos camales ubicados en el valle de Lima, en los meses de marzo, abril y mayo de 1999. Los animales eran de raza cruzada, de 8 a 9 meses de edad y provenían de granjas de crianza artesanal de 4 distritos del Sur de Lima.

Las muestras eran recolectadas en frascos de vidrio estériles, y llevadas, después de ser rotuladas, al Laboratorio de Patología Clínica de la Facultad de Medicina Veterinaria de la UNMSM; donde se centrifugaron para separar el suero de los elementos formes, guardándose en el congelador a $10^{\circ} \mathrm{C}$ para su análisis serológico posterior.

Para la prueba serológica se empleo un kit comercial de inmunoensayo por enzima (ELISA) para la detección de anticuerpos contra el patógeno de la neumonía enzoótica porcina (M. hyopneumoniae) en el suero sanguíneo porcino. La lectura de las absorbancias 
de cada pozo se realizó en un lector automático de ELISA (Uniskan II), con filtro a $405 \mathrm{~nm}$.

Los resultados obtenidos en las pruebas fueron expresados en proporciones y porcentajes, teniéndose en consideración la positividad de los sueros a la prueba, estableciéndose además su intervalo de confianza. Asimismo, para determinar la asociación entre la presencia de seroreactores positivos a la prueba de ELISA y el área geográfica de donde provenían las muestras se empleó la prueba de Chi Cuadrado.
El M. hyopneumoniae se encuentra presente en los cerdos provenientes de granjas de crianza artesanal del Sur de Lima. De un total de 160 muestras de suero de cerdos obtenidas en el camal se encontró que el $11.25 \%$ (18/160) fueron seroreactores positivos al microorganismo (Cuadro 1 ). Resultado que se asemeja al obtenido por Huallanca (1999) quien obtuvo en siete granjas una frecuencia de 12.2. Solo el $5 \%$ de los animales presentaron lesiones típicas de neumonía enzoótica al momento de ser beneficiados.

Cuadro 1. Resultado de porcinos reactores a Mycoplasma. hyopneumoniae procedentes de Lima, mediante la prueba de ELISA.

\begin{tabular}{lccc}
\hline Distrito & Muestras & \multicolumn{2}{c}{ Positivos } \\
\cline { 3 - 4 } & $\mathrm{n}$ & $\mathrm{n}$ & $\%$ \\
\hline Villa El Salvador & 46 & $\mathbf{8}$ & 17.4 \\
San Juan de Miraflores & 41 & 6 & 14.6 \\
Pachacamac & 37 & 2 & 5.4 \\
Lurín & 36 & 2 & 5.6 \\
& & & 11.25 \\
\hline Total & 160 & $\mathbf{1 8}$ & \\
\hline
\end{tabular}

De los 4 distritos de donde provenían los animales, el rango de animales positivos varió de $5.4 \%$ a $17.4 \%$.

No se encontró asociación estadística $(P>0.05)$ entre la presencia de seroreactores positivos y el área geográfica de donde provenían las muestras.

El M. hyopneumoniae se presenta mayormente en granjas con alta densidad de población, una ventilación inadecuada y niveles elevados de amoníaco en la atmósfera. Estos factores, en la mayoría de los casos, no se presentan en las granjas de crianza de tipo artesanal, en las que el principal inconveniente está relacionado a las condiciones sanitarias deficientes. Además, existen otros factores condicionantes para la presentación de neumonía enzoótica en granjas de crianza artesanal; uno de los cuales es el retraso del destete de lechones que aumenta las oportunidades de transmisión vertical de esta enfermedad. Otro factor es el mantenimiento de animales de diferentes edades en un mismo corral, que aumentan las posibilidades de transmisión horizontal.

También se ha señalado que la temperatura y la humedad modifican la capacidad de penetración del microorganismo a los pulmones, porque alteran el tamaño de las partículas de aerosoles infectadas y el mecanismo protector de las vías respiratorias, además de alterar la sedimentación de dichas partículas. Los cerdos de crianza artesanal al ser sometidos a fluctuaciones de temperatura ambiental, corrientes frías y mala 
nutrición son por lo tanto más propensos a sufrir esta enfermedad.

En cuanto a la presencia de neumonía en los pulmones de los animales muestreados, aunque este no fue el objetivo del presente estudio, se pudo observar que existían lesiones neumónicas típicas de neumonía enzoótica (con lesiones en los lóbulos apical y cardiaco) con una frecuencia muy baja, menor al $5 \%$.

$\mathrm{Al}$ respecto, en un trabajo previo realizado en mataderos de nuestro país. (Vega, 1969) se obtuvo una prevalencia de lesiones del $40 \%$ en animales que procedían de explotaciones intensivas.

La baja frecuencia de lesiones neumónicas típicas de neumonía enzoótica se debe a que, en caso de los animales de granjas tecnificadas, estos alcanzan su peso de beneficio a los 5 meses de edad en promedio. En cambio en los animales de crianza no tecnificada, estos lo logran a los 8 a 9 meses, y tal como lo mencionan Blood et al., (1992), la prevalencia de lesiones neumónicas en explotaciones intensivas alcanza su pico máximo a los 60 a $65 \mathrm{~kg}$ de peso corporal, y luego declina constantemente hasta un nivel muy bajo, por lo que la edad y el peso son factores que se deben tomar en cuenta.

Por otro lado, el hecho de que estos animales no sean de una raza determinada influye también en la menor presentación de la enfermedad. Al respecto Gardner y Hird, (1990) al hacer un estudio sobre los factores determinantes de neumonía en cerdos beneficiados, indicó que la heterosis ofrecía protección contra la presentación de neumonía.

No se halló asociación estadística entre la presencia de seroreactores positivos y el área geográfica de donde provenían los animales; lo que explica que el $M$. hyopneumoniae se encuentra ampliamente distribuido en todos los lugares de crianza porcina.
En base a los resultados obtenidos se concluye que el $M$. hyopneumoniae está presente en la explotación porcina artesanal. Aunque esta presencia no es de la magnitud que se reporta en otras partes del mundo, creemos que a medida que la producción porcina extensiva o semiextensiva pase a ser intensiva, y no se tomen medidas adecuadas para su control, su presencia irá en aumento. Por último las lesiones neumónicas no siempre son indicativas del grado de la enfermedad, a nivel individual; por lo tanto, es mejor evaluar para un mejor diagnóstico las lesiones a nivel de la piara.

\section{Bibliogratia}

1. Ahlbom, A. y S. Norell. 1990. Introduction to modern epidemiology. Second Edition, p. 24-9. Epidemiology Resources Inc.

2. Amass, S.F.; L.K. Clark; W.G. Van Alstine; T.L. Bowersock; D.A. Murphy; K.E. Knox y S.R. Albregts. 1994. Interaction of Mycoplasma hyopneumoniae and Pasteurella multocida infections in swine. $J A V M A$, 204(1):102-7.

3. Blood, D.C.; O.M. Radostits; J.H. Arundel y C.C. Gay. 1992. Medicina Veterinaria. $8^{a}$ ed., p.843-9. Ed. Interamericana Mc Graw Hill, Madrid.

4. Boeckman, S. 1996. Grow-Finish herds hit hard by porcine respiratory disease complex. Swine Practitioner Feb:4-8.

5. Carusso, J.P. y R.F. Ross. 1990. Effects of Mycoplasma hyopneumoniae and Actinobacillus (Haemophilus) pleuropneumoniae infections on alveolar macrophage functions in swine. $A m J$ Vet Res, 51(2):227-30.

6. Copes, J.; F. Nievas; R. Cerda y C. Perfumo. 1995. Aislamiento y caracterización de Mycoplasma sp. de pulmones de cerdos provenientes de mataderos. Analecta Veterinaria, 15(1)27-30.

7. Dee, S.A. 1997. Porcine respiratory disease complex: The "18 Week Wall". Pigs-Misset; 13(1)18-9. 
8. Gardner, I.A. y D.W. Hird. 1990. Host determinants of pneumonia in slaughter weight swine. Am J Vet Res, 51(8)130611.

9. Hill, M.A.; A.B. Scheidt; R.F. Teclaw; L.K. Clark; K.E. Knox y M. Jordan. 1992. Association between growth indicators and volume of lesions in lungs from pigs at slaughter. Am $J$ Vet Res, 53(1)2221-3.

10. Huallanca, O.A.C. 1999. Determinación de reactores a Mycoplasma hyopneumoniae en cerdos sacrificados en un camal frigorífico. Tesis Bachillerato Fac. Med. Vet. Universidad Nacional Mayor de San Marcos, Lima. 30 p.
11. Kobisch, M. $y$ N.F. Friis. 1996. Swine mycoplasmoses. Rev Sci Tech, 15(4):1569-605.

12. Stipkovits, L. 1995. Neumonía por Micoplasma en el cerdo PIGS-Misset, Sep:18-19.

13. Torres, P.L. 1992. Lesiones pulmonares que determinan el decomiso íntegro del pulmón de porcino. Tesis Bachillerato Fac. Med. Vet. Univ. Nac. Mayor de San Marcos. Lima. 39 Pág.

14. Vega, GI. 1969. Neumonía porcina. Estudio bacteriológico y anatomohistopatológico. Bachillerato Fac. Med. Vet: Univ. Nac. Mayor de San Marcos. Lima, 55 . 